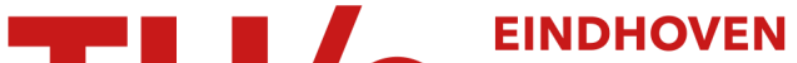

\section{Winding topologies of flux-switching motors for in-wheel traction}

Citation for published version (APA):

Tang, Y., Paulides, J. J. H., \& Lomonova, E. A. (2015). Winding topologies of flux-switching motors for in-wheel traction. COMPEL: The International Journal for Computation and Mathematics in Electrical and Electronic

Engineering, 34(1), 32-45. https://doi.org/10.1108/COMPEL-11-2013-0377

DOI:

10.1108/COMPEL-11-2013-0377

Document status and date:

Published: 01/01/2015

\section{Document Version:}

Publisher's PDF, also known as Version of Record (includes final page, issue and volume numbers)

\section{Please check the document version of this publication:}

- A submitted manuscript is the version of the article upon submission and before peer-review. There can be important differences between the submitted version and the official published version of record. People interested in the research are advised to contact the author for the final version of the publication, or visit the $\mathrm{DOI}$ to the publisher's website.

- The final author version and the galley proof are versions of the publication after peer review.

- The final published version features the final layout of the paper including the volume, issue and page numbers.

Link to publication

\section{General rights}

Copyright and moral rights for the publications made accessible in the public portal are retained by the authors and/or other copyright owners and it is a condition of accessing publications that users recognise and abide by the legal requirements associated with these rights.

- Users may download and print one copy of any publication from the public portal for the purpose of private study or research.

- You may not further distribute the material or use it for any profit-making activity or commercial gain

- You may freely distribute the URL identifying the publication in the public portal.

If the publication is distributed under the terms of Article 25fa of the Dutch Copyright Act, indicated by the "Taverne" license above, please follow below link for the End User Agreement:

www.tue.nl/taverne

Take down policy

If you believe that this document breaches copyright please contact us at:

openaccess@tue.nl

providing details and we will investigate your claim. 
COMPEL 34,1

\section{2}

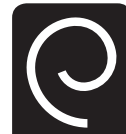

Emerald

COMPEL: The International Journal for Computation and Mathematics in Electrical and Electronic Engineering

Vol. 34 No. 1,2015

pp. $32-45$

(C) Emerald Group Publishing Limited $0332-1649$

DOI 10.1108/COMPEL-11-2013-0377

\section{Winding topologies of flux-switching motors for in-wheel traction}

\author{
Y. Tang, J.J.H. Paulides and E.A. Lomonova \\ Electromechanics and Power Electronics Group, \\ Department of Electrical Engineering, Eindhoven University of Technology, \\ Eindhoven, The Netherlands
}

\begin{abstract}
Purpose - The purpose of this paper is to investigate winding topologies for flux-switching motors (FSMs) with various segment-tooth combinations and different excitation methods.

Design/methodology/approach - For the ac winding of FSM, two winding topologies, namely the concentrated winding and the distributed winding, are compared in terms of the winding factor and efficiency. For the field winding of dc-excited FSM (DCEFSM), another two winding topologies, namely the lap winding and the toroidal winding, are compared in terms of effective coil area, end-winding length, and thermal conditions. Analytical derivation is used for the general winding factor calculation. The calculation results are validated using finite element analysis.

Findings - Winding factors can be used as an indication of winding efficiency for FSMs in the same manner as done for synchronous motors. For FSMs with concentrated windings, the winding factor increases when the rotor tooth number approaches a multiple of the stator segment number. For FSMs with certain segment-tooth combinations, e.g. $6 / 8$, the theoretical maximum winding factor can be achieved by implementing distributed windings. Furthermore, the toroidal winding can be an efficient winding topology for DCEFSMs with large stator diameter and small stack length.

Research limitations/implications - This work can be continued with investigating the variation of reluctance torque with respect to different segment-tooth combinations of FSM.

Originality/value - This paper proposes a general method to calculate the winding factor of FSMs using only the phase number, the stator segment number, the rotor tooth number, and the skew angle. Using this method, a table of winding factors of FSMs with different segment-tooth combinations is provided. Principle of design of FSMs with high-winding factors are hence concluded. This paper also proposed the implementation of distributed windings for FSM with certain segment-tooth combinations, e.g. $6 / 8$, by which means a theoretical maximum winding factor is achieved. In addition, different winding topologies for the field winding of DCEFSM are also investigated.
\end{abstract}

Keywords Topology, Electrical machines, Brushless motors

Paper type Research paper

\section{Introduction}

With the rise of public interest in hybrid-electric vehicles and electric vehicles, in-wheel traction becomes an attractive concept as it brings a high degree of simplicity and stability to the vehicle system design (Ehsani et al., 2007; Zhu and Howe, 2007).

There are mainly two types of in-wheel traction modules, namely direct drive and indirect drive. In a direct drive module, the electrical motor is directly driving the wheel without a gearbox, as shown in Figure 1(a). This direct drive module provides a maximum simplicity for the system design, however, requires a high torque from the traction motor. The high-torque requirement increases the volume and mass of the traction motor and consequently reduces the passenger comfort (Lomonova et al., 2011). While, in an indirect drive module, the electrical motor is indirectly driving the wheel through a gearbox, as shown in Figure 1(b). By this means the torque requirement for the motor is reduced and 
the wheel mass can be maintained. However, compared to the direct drive module, a wider speed range is usually required for the motor in the indirect drive module.

Besides the strict requirement of torque production or speed range, in both types of in-wheel traction modules electric motors need to have high-torque density with certain level of ruggedness. Therefore, in-wheel traction raises the challenge for motor selection and design (Figure 2).

Flux-switching motors (FSMs), including flux-switching permanent magnet motors, and dc-excited flux-switching motors (DCEFSM), are considered as a strong candidate because of their inherent ruggedness, high-torque density, and wide speed range (Tang et al., 2010; Ilhan et al., 2010). However, available publications mostly focus on limited combinations of stator-segment number $N_{\mathrm{s}}$ and rotor-tooth number $N_{\mathrm{r}}$ with

\section{Winding topologies of flux-switching motors}

33
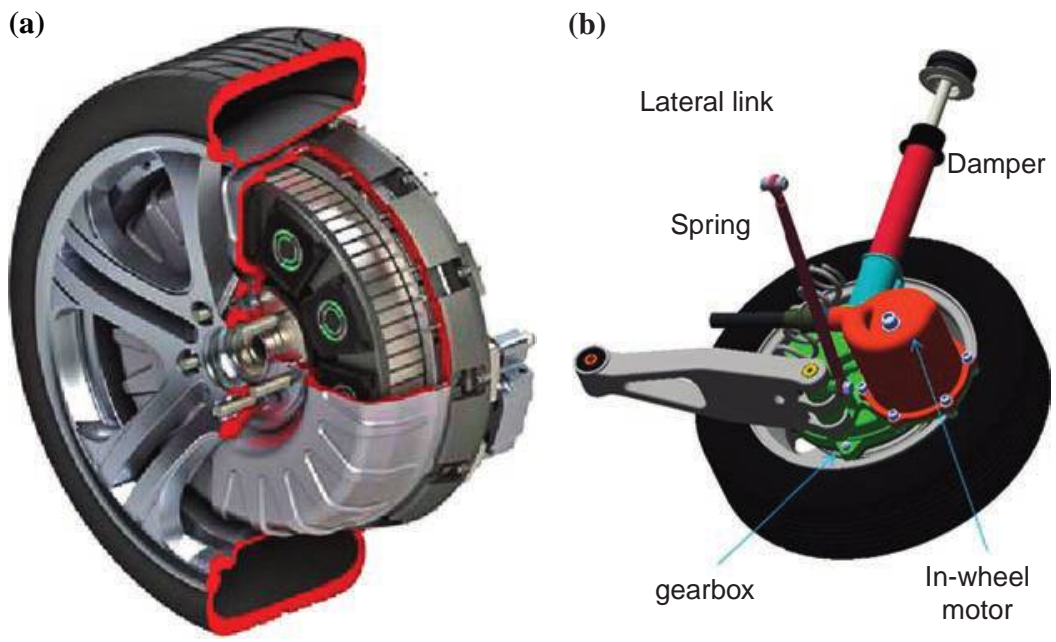

Notes: (a) Direct drive (protean in-wheel motor); (b) indirect drive

Figure 1. In-wheel traction

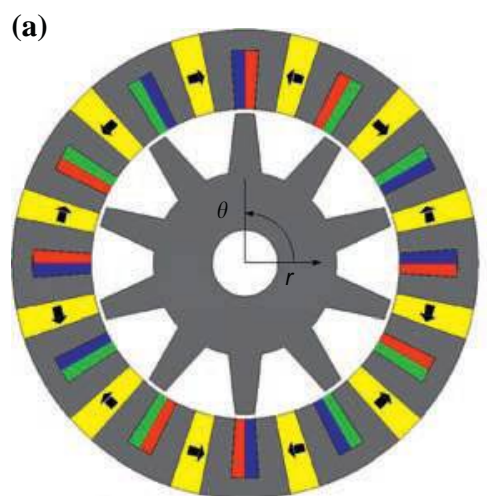

Three-phase armature windings Permanent magnets

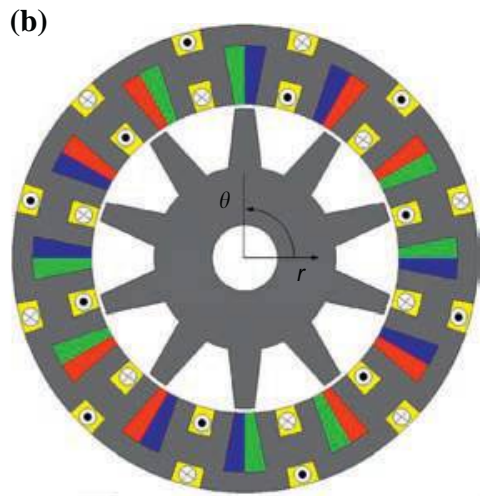

Ferromagnetic material Dc field windings
Figure 2.

Cross-sections of (a) flux-switching permanent magnet motor (FSPMM); and (b) dc-excited flux-switching motor

(DCEFSM) with toroidal field windings 
COMPEL only concentrated windings. The impact of different segment-tooth combinations and 34,1 winding topologies on the performance of FSMs still needs to be investigated.

In permanent magnet synchronous motors (PMSMs), the winding factor $k_{\mathrm{w}}$ provides a good indication of the percentage of the rotating flux wave that the windings actually link, or in other words, the percentage of the magnetomotive force (MMF) that effectively contributes to the torque generation, thus it is one of the criteria for the winding efficiency assessment. In FSMs, despite of different principle of torque production, the waveform of phase flux linkage is similar to PMSMs. Thus, the winding factor can also be used to rate different winding topologies for this type of machines. As such, Chen and Zhu (2010) introduced a series of equations and calculated the winding factors for certain FSMs as the ratio between the vector summation and the algebraic summation of their coil electromotive forces (EMFs). However, to implement these equations, a few parameters need to be calculated first, such as the number of coil-EMF phasors per phase $Q$ and the electrical angle between two adjacent phasors $\alpha$. These parameters vary with the configurations of FSMs, yet the correlation is not obvious, hence they have to be calculated individually for every different case. The lack of generalization makes the winding factor calculation time-consuming when repeated with different parameters.

This paper proposes a general method for calculating the winding factor of flux switching motors (FSMs) using only the phase number $m$, the stator-segment number $N_{\mathrm{s}}$, the rotor-tooth number $N_{\mathrm{r}}$, and the skew angle. With this method, winding factors of FSMs with different segment-tooth combinations are calculated. Based on the obtained winding factors, different winding topologies for ac armature windings are investigated. The results show that for certain segment-tooth combinations, FSMs with distributed windings can achieve a higher winding fact than with concentrated windings. The improvement in winding factor resulting from implementation of different winding topologies is validated using finite element analysis (FEA). Furthermore, for DCEFSM, two types of dc field winding topologies, namely lap winding and toroidal winding, are compared.

\section{Winding factor calculation}

For ac windings, the winding factor is a fractional number indicating the decrease in the total MMF, flux linkage and thus torque production due to different placement of coil conductors compared to implementing single non-skewed full-pitch coil for each phase. This factor is positively related to the torque constant of a motor, i.e. the ratio between the generated electromagnetic torque and the required armature current, hence it is a significant criterion for the motor design.

For FSMs, the winding factor $k_{\mathrm{w}}$ can be calculated as a product of the distribution factor $k_{\mathrm{d}}$, the pitch factor $k_{\mathrm{p}}$ and the skew factor $k_{\mathrm{s}}$, i.e:

$$
k_{\mathrm{w}}=k_{\mathrm{d}} k_{\mathrm{p}} k_{\mathrm{s}},
$$

which is comparable to that for PMSMs.

The three factors can be, respectively, calculated as:

$$
\begin{gathered}
k_{\mathrm{d}}=\frac{\sin (Q \alpha / 2)}{Q \sin (\alpha / 2)}, \\
k_{\mathrm{p}}=\left|\cos \frac{\theta_{\mathrm{c}}}{2}\right|,
\end{gathered}
$$




$$
k_{\mathrm{S}}=\frac{\sin (\sigma / 2)}{\sigma / 2},
$$

In which $Q$ is the number of coil EMF phasors per phase, $\alpha$ is the electrical angle between two adjacent phasors, $\theta_{c}$ is the electrical angle between the EMF phasors of the two conductors in a coil, and $\sigma$ is the skew angle.

The skew factor $k_{\mathrm{S}}$ can be directly obtained when the skew angle $\sigma$ is decided. However, to obtain the distribution factor $k_{\mathrm{d}}$ and the pitch factor $k_{\mathrm{p}}$, the parameters $Q$, $\alpha$, and $\theta_{\mathrm{c}}$ need to be calculated first. These parameters vary according to the segmenttooth combination of FSMs, yet the correlation is not obvious, hence they have to be calculated individually for every different case. The lack of generalization makes the procedure of winding factor calculation very difficult to program and thus timeconsuming when repeated with different parameters.

This paper proposes a general method for calculating the winding factors of FSMs. With this method, the parameters $Q, \alpha$, and $\theta_{\mathrm{c}}$ in (2) and (3) can be derived from the phase number $m$, the stator-segment number $N_{\mathrm{s}}$, the rotor-tooth number $N_{\mathrm{r}}$, and the skew angle $\sigma$, thus the calculation procedure can be easily programmed and repeated.

\subsection{Parameter definition}

The least motor parameters required for the winding factor calculation are listed below. For comparison, certain parameters are differently defined in PMSM and in FSM:

- $m$ : number of ac-winding phases;

- $N_{\mathrm{s}}$ : number of stator slots (PMSM) or stator segments (FSM);

- $N_{\mathrm{r}}$ : number of rotor poles (PMSM) or rotor teeth (FSM); and

- $\sigma$ : skew angle.

Using these four basic parameters, following parameters are derived:

- $\quad \beta$ : slot pitch in PMSM or segment pitch in FSM.

In PMSM:

$$
\beta=\frac{2 \pi p}{N_{\mathrm{s}}}=\frac{\pi N_{\mathrm{r}}}{N_{\mathrm{s}}},
$$

in which $p$ is the number of pole-pairs, or in other words, the number of electrical periods per rotor revolution.

In FSM, however, the number of electrical periods per rotor revolution is equal to the number of rotor teeth $N_{\mathrm{r}}$. Therefore, in this motor the segment pitch $\beta$ is calculated as:

$$
\beta=\frac{2 \pi N_{\mathrm{r}}}{N_{\mathrm{s}}},
$$

- Greatest common divisor (GCD) of $N_{\mathrm{s}}$ and $N_{\mathrm{r}}$ :

$$
t=G C D\left(N_{\mathrm{s}}, N_{\mathrm{r}}\right),
$$

- Co-prime integers derived from $N_{\mathrm{s}}$ and $N_{\mathrm{r}}$ :

$$
N_{\mathrm{s}}^{\prime}=N_{\mathrm{s}} / t
$$


COMPEL 34,1

36

$$
N_{\mathrm{r}}^{\prime}=N_{\mathrm{r}} / t,
$$

- Number of slots/segments per phase per half electrical period:

$$
q=\frac{N_{\mathrm{s}}}{2 m N_{\mathrm{r}}}=\frac{N_{\mathrm{s}}^{\prime}}{2 m N_{\mathrm{r}}^{\prime}}=\frac{b}{c},
$$

where $b$ and $c$ are co-prime integers.

- A prime winding:

A prime winding is defined as a part of the winding that represents the electromagnetic periodicity of the whole winding. In this FSM, a prime winding is corresponding to $N_{\mathrm{s}}^{\prime}$ segments an $p^{\prime}$ rotor pole pairs or teeth, because the electrical angle between any $k$ th segment and $\left(k+N_{\mathrm{s}}^{\prime}\right)$ th segment is:

$$
\beta_{k\left(k+N_{\mathrm{s}}^{\prime}\right)}=N_{\mathrm{s}}^{\prime} \beta=2 \pi N_{\mathrm{r}}^{\prime},
$$

which is a multiple of $2 \pi$.

\subsection{Calculation of the distribution factor $k_{d}$}

To calculate the distribution factor using (2), the number of coil EMF phasors per phase $Q$ and the angle between adjacent phasors $\alpha$ need to be obtained first. These two parameters are dependent on the number of coils per phase in a prime winding, i.e. $N_{\mathrm{s}}^{\prime} / m$, which must be an integer to balance the phases.

If $N_{s}^{\prime} / m$ is odd, such as the example shown in Figure 3(a), the EMF phasor of a counter connected coil is always in the middle of another two adjacent EMF phasors of direct connected coils. Hence, $Q$ and $\alpha$ are obtained as:

$$
\begin{gathered}
Q=N_{\mathrm{s}}^{\prime} / m \\
\alpha=\left(2 \pi / N_{\mathrm{s}}{ }^{\prime}\right) / 2=\pi / N_{\mathrm{s}}{ }^{\prime}
\end{gathered}
$$

(a)

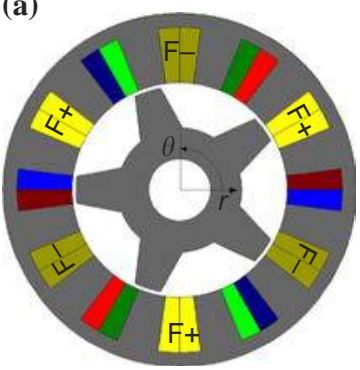

(b)

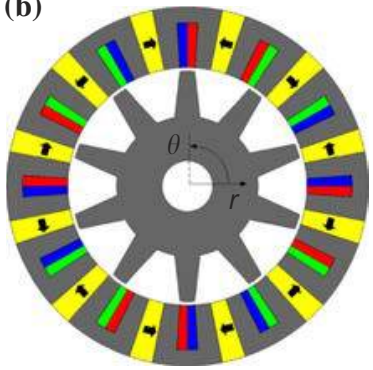

(c)

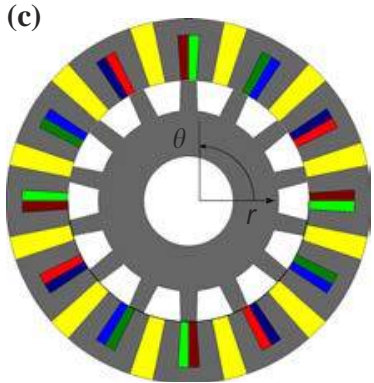

Notes: (a) 6/5 DCEFSM, 6-stator-segment, 5-rotor-tooth dc-excited flux-switching motor (DCEFSM); (b) 12/10 FSPMM, 12-stator-segment, 10-rotor-tooth flux-switching permanent magnet motor (FSPMM); (c) 12/14 FSPMM, 12-stator-segment, 14-rotor-tooth FSPMM 
If $N_{\mathrm{s}}^{\prime} / m$ is even, such as the example shown in Figure 3(b), the EMF phasor of a counter connected coil is always overlapped with another EMF phasor of a direct connected coil. Hence, $Q$ and $\alpha$ are obtained as (Figure 4):

$$
\begin{gathered}
Q=N_{\mathrm{s}}^{\prime} / 2 m \\
\alpha=2 \pi / N_{\mathrm{s}}^{\prime}
\end{gathered}
$$

Equations (12)-(15) can be further generalized using (10):

- when $N_{\mathrm{s}}^{\prime} / m$ is odd, $N_{\mathrm{s}}^{\prime} / m=b$ and $2 N_{\mathrm{r}}^{\prime}=c$; and

- when $N_{\mathrm{s}}^{\prime} / m$ is even, $N_{\mathrm{s}}^{\prime} / 2 m=b$ and $N_{\mathrm{r}}^{\prime}=c$.

Therefore, in both cases:

$$
\begin{gathered}
Q=b \\
\alpha=\pi / m b
\end{gathered}
$$

Including (16) and (17) into (2), the fundamental distribution factor of an FSM can thus be uniformly calculated as:

$$
k_{\mathrm{d}}=\frac{\sin (\pi / 2 m)}{b \sin (\pi / 2 m b)}
$$

\subsection{Calculation of the pitch factor $k_{p}$}

To calculate the pitch factor using (3), the electrical angle between the EMF phasors of the two conductors in a coil $\theta_{c}$ needs to be obtained first. This angle can be calculated as:

$$
\theta_{c}=n_{\mathrm{sp}} \gamma-\pi
$$

(a)

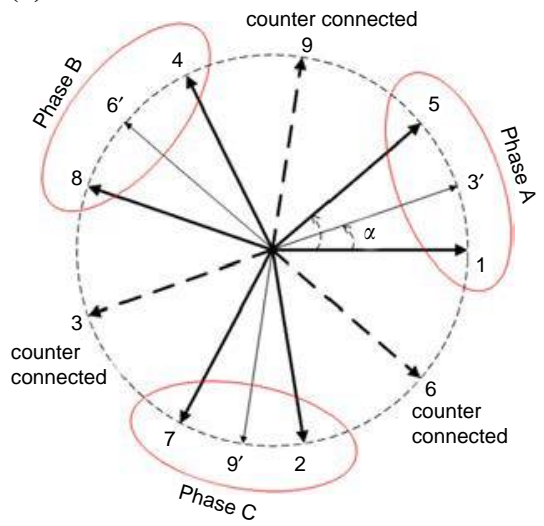

(b)

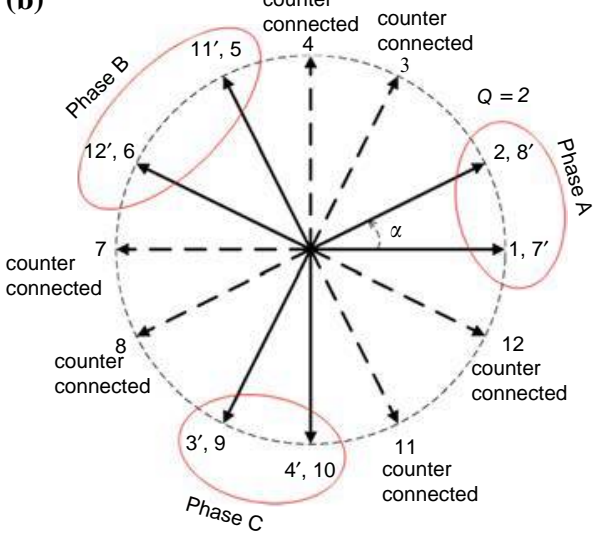

Notes: (a) $18 / 16 \mathrm{FSM}, N_{\mathrm{s}}^{\prime} / m=3,18$ stator segments/16 rotor teeth; (b) 24/26 FSM, $N_{\mathrm{s}}^{\prime} / m=4,24$ stator segments $/ 26$ rotor teeth

Winding topologies of flux-switching motors 37 
COMPEL In which $\gamma$ is the phase shift between two adjacent slots (PMSM) or segments (FSM) in 34,1

the fundamental harmonic of air gap magnetic field, $n_{\mathrm{sp}}$ is the number of slots in a PMSM or segments in an FSM between the two conductors of a coil, and $-\pi$ indicates the opposite current-conducting direction in the two conductors.

In PMSM, the phase shift angle $\gamma$ is equal to the slot pitch, i.e.:

$$
\gamma=\beta .
$$

In FSM, however, the reversal of flux polarity between adjacent segments should also be taken into account. The principle is illustrated in Figure 5(a) and (b), in which $\omega$ is the electrical angular speed of the rotor, and $\theta_{1}$ and $\theta_{2}$ are the electrical angular positions of two adjacent segments in an electrical period. Hence: $\theta_{2}-\theta_{1}=\beta$. The air gap flux densities at $\theta_{1}$ and $\theta_{2}$ can be approximately described as:

$$
\begin{gathered}
B_{\theta 1}(\omega t)=B_{0}+B_{\mathrm{m}} \sin \left(\omega t-\theta_{1}\right) \\
B_{\theta 2}(\omega t)=-B_{0}-B_{\mathrm{m}} \sin \left(\omega t-\theta_{2}\right)=-B_{0}+B_{\mathrm{m}} \sin \left(\omega t-\theta_{2}-\pi\right)
\end{gathered}
$$

Therefore, the phase shift angle $\gamma$ between the fundamental harmonics of $B \theta_{1}$ and $B \theta_{2}$ is:

$$
\gamma=\left(\theta_{2}+p\right)-\theta_{1}=\beta+\pi
$$

(a)

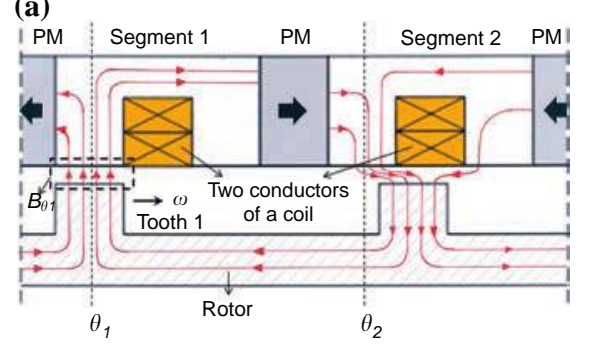

(b)

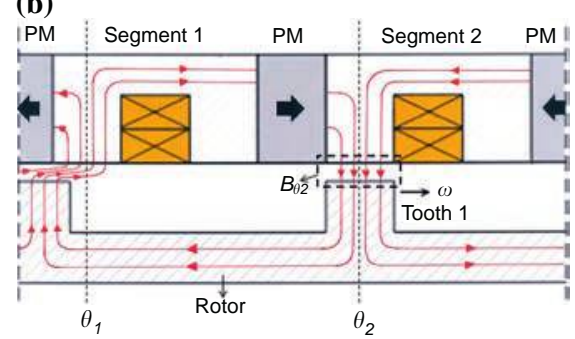

Figure 5.

Comparison of air gap flux densities under two adjacent segments of a 12/10 FSM

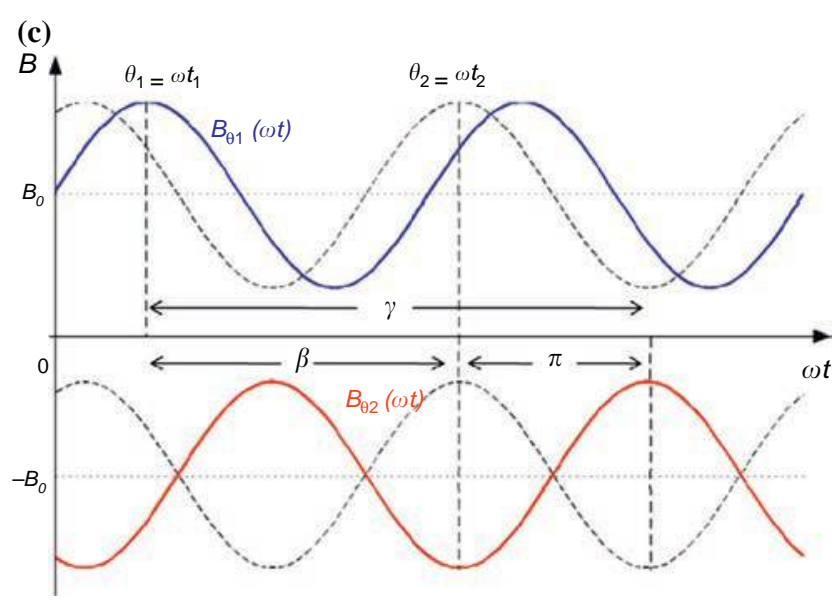

Notes: (a) $t=t 1$ : Rotor-tooth 1 aligned with Segment 1 ; (b) $t=t 2$ : Rotor-tooth 1 aligned with Segment 2; (c) air gap flux densities under Segment 1 and Segment 2 
Integrating (6), (19), (23) into (3), the pitch factor $k_{\mathrm{p}}$ of FSM is calculated as:

$$
k_{\mathrm{p}}=\left|\cos \frac{n_{\mathrm{sp}}(\beta+\pi)-\pi}{2}\right|=\left|\cos \left(\frac{n_{\mathrm{sp}} N_{\mathrm{r}}}{N_{\mathrm{s}}} \cdot \pi+\frac{\left(n_{\mathrm{sp}}-1\right) \pi}{2}\right)\right|
$$

This can be compared to the expression of the pitch factor for PMSM, obtained by integrating (6), (19), (20) into (3):

$$
k_{\mathrm{p}}=\left|\cos \frac{n_{\mathrm{sp}} \beta-\pi}{2}\right|=\left|\cos \left(\frac{n_{\mathrm{sp}} N_{\mathrm{r}}}{N_{\mathrm{s}}} \cdot \frac{\pi}{2}-\frac{\pi}{2}\right)\right|=\left|\sin \left(\frac{n_{\mathrm{sp}} N_{\mathrm{r}}}{N_{\mathrm{s}}} \cdot \frac{\pi}{2}\right)\right|
$$

In concentrated windings: $n_{\mathrm{sp}}=1$, thus (24) and (25) are simplified.

For FSM with concentrated windings:

$$
k_{\mathrm{p}}=\left|\cos \left(\frac{N_{\mathrm{r}}}{N_{\mathrm{s}}} \cdot \pi\right)\right|
$$

For PMSM with concentrated windings, as in comparison:

$$
k_{\mathrm{p}}=\left|\sin \left(\frac{N_{\mathrm{r}}}{N_{\mathrm{s}}} \cdot \frac{\pi}{2}\right)\right| .
$$

\subsection{Winding factor table for FSMS}

Using the Equations (1), (18), and (26), winding factors of FSMs with concentrated windings and different combinations of stator-segment number $N_{\mathrm{S}}$ and rotor-tooth number $N_{\mathrm{r}}$ are calculated and presented in Table I.

Based on the results in Table I, rules in choosing appropriate stator-segment number $N_{\mathrm{S}}$ and rotor-tooth number $N_{\mathrm{r}}$ for FSMs can be summarized as follows:

- To balance the three phases and the two magnetic poles, $N_{s}$ should always be a multiple of 6, i.e. $N_{\mathrm{s}}=6 n,(n \in \mathbb{N})$.

- Even if $N_{\mathrm{s}}$ is a reasonable number, some combinations with $N_{\mathrm{r}}$ still cannot give a balanced winding. For these combinations, the winding factor are not calculated.

- For each possible $N_{\mathrm{s}}$, the winding factor increases when $N_{\mathrm{r}}$ approaches $n N_{\mathrm{s}}(n \in \mathbb{Z})$.

\section{Concentrated windings vs distributed windings}

For FSM with concentrated windings, only a limited number of combinations can provide a relatively large winding factor, such as $12 / 10$ and 12/14, as presented in Table I.

\begin{tabular}{clllllllllll}
\hline$N_{\mathrm{r}} / N_{\mathrm{s}}$ & $N_{\mathrm{s}} \pm 11$ & $N_{\mathrm{s}} \pm 10$ & $N_{\mathrm{s}} \pm 9$ & $N_{\mathrm{s}} \pm 8$ & $N_{\mathrm{s}} \pm 7$ & $N_{\mathrm{s}} \pm 6$ & $N_{\mathrm{s}} \pm 5$ & $N_{\mathrm{s}} \pm 4$ & $N_{\mathrm{s}} \pm 3$ & $N_{\mathrm{s}} \pm 2$ & $N_{\mathrm{s}} \pm 1$ \\
\hline & & & & & & & & & & & \\
6 & $0.866^{*}$ & $0.5^{*}$ & & $0.5^{*}$ & $0.866^{*}$ & & 0.866 & 0.5 & & 0.5 & 0.866 \\
12 & $0.933^{*}$ & 0.866 & & 0.5 & 0.25 & & 0.25 & 0.5 & & 0.866 & 0.933 \\
18 & 0.328 & 0.167 & & 0.167 & 0.328 & 0.5 & 0.617 & 0.735 & 0.866 & 0.902 & 0.945 \\
24 & 0.125 & 0.25 & & 0.5 & 0.583 & & 0.760 & 0.866 & & 0.933 & 0.950
\end{tabular}

Notes: The rotor-tooth number $N_{\mathrm{r}}$ should be larger than 1 , hence for the grids indicated with a * only one combination is practically valid
Winding topologies of flux-switching motors 
COMPEL 34,1

\section{0}

Table II.

Fundamental three-phase distributed windings harmonic winding 6 factors of FSMs with 12

However, even with these combinations the winding factor still cannot reach the theoretical maximum value: $k_{\mathrm{w}}=1$. This is because $N_{\mathrm{r}}$ cannot be a multiple of the statorsegment number $N_{\mathrm{s}}$, hence the pitch factor $k_{\mathrm{p}}$ is always smaller than 1 according to (26).

However, the maximum winding factor can be achieved when distributed windings are implemented into FSMs with certain segment-tooth combinations. In distributed windings, a coil is wound over more segments to obtain a larger flux-linkage.

Using (26), a few possible combinations of $N_{\mathrm{S}}$ and $N_{\mathrm{r}}$ for FSMs are found out, with which the maximum winding factor: $k_{\mathrm{w}}=1$ can be achieved when $n_{\mathrm{sp}}=3$, as presented in Table II.

According to Tables I and II, with distributed windings, the winding factor of 12/16 FSM achieves the maximum value: $k_{\mathrm{w}}=1$, which is twice the winding factor of the same FSM with concentrated windings. The advantage of distributed windings

To verify the difference in the winding factor between concentrated windings and distributed windings, two 6/8 DCEFSM models with each winding topology, shown in Figure 6, are analyzed using FEA. Motor dimensions used for the modeling are summarized in Table III.

Figure 7(a) shows the waveforms of open-circuit phase flux linkage of the two motor models. It can be seen that the magnitude of phase flux linkage in 6/8 FSM with distributed windings is visibly higher than that of the motor with concentrated windings. The harmonic analysis using Fourier series is further shown in Figure 7(b). The magnitude of the fundamental harmonic phase flux linkage for distributed windings is twice the corresponding harmonic for concentrated windings, which matches the ratio between the expected winding factors of the two winding topologies.

\begin{tabular}{lllllllll}
\hline$N_{\mathrm{r}} / N_{\mathrm{s}}$ & $N_{\mathrm{s}}-8$ & $N_{\mathrm{s}}-6$ & $N_{\mathrm{s}}-4$ & $N_{\mathrm{s}}-2$ & $N_{\mathrm{s}}+2$ & $N_{\mathrm{s}}+4$ & $N_{\mathrm{s}}+6$ & $N_{\mathrm{s}}+8$ \\
\hline
\end{tabular}

\section{Figure 6.}

Cross-sections of $6 / 8$ dc-excited flux-switching motors (FSM) with indication of different ac winding topologies
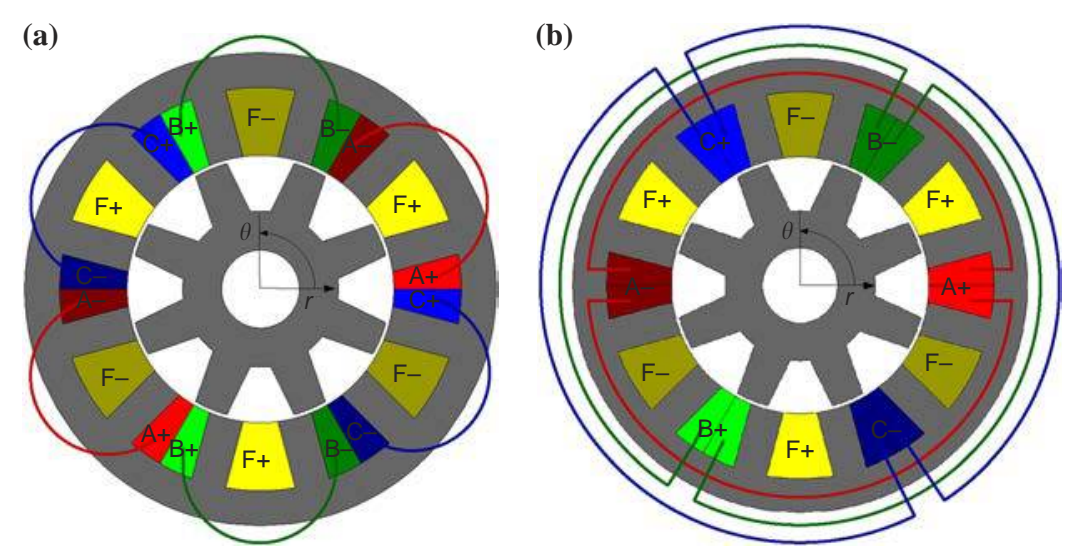

Notes: (a) Concentrated windings; (b) distributed windings 
In Figure 8, FEA results of the electromagnetic torque of the 6/8 DCEFSM with each winding topology are compared. In general, the torque of the DCEFSM increases when the winding topology changes from the concentrated winding to the distributed winding. Especially at low-current densities when the stator is unsaturated, the torque of the DCEFSM with distributed windings is almost twice of that of the motor

\begin{tabular}{|c|c|c|c|c|}
\hline Parameter & Symbol & Value & Unit & 41 \\
\hline Stator outer diameter & $D_{\mathrm{so}}$ & 127.5 & $\mathrm{~mm}$ & $\begin{array}{l}\text { Table III. } \\
\text { Fundamental }\end{array}$ \\
\hline Stack length & $\stackrel{D_{\text {so }}}{L}$ & 90.0 & $\mathrm{~mm}$ & harmonic winding \\
\hline Stator back iron height & $h_{\mathrm{si}}$ & 9.4 & $\mathrm{~mm}$ & factors of FSMs \\
\hline Rotor outer diameter & $D_{\mathrm{ro}}$ & 70.0 & $\mathrm{~mm}$ & with three-phase \\
\hline Airgap length & $\delta$ & 1.0 & $\mathrm{~mm}$ & distributed windings \\
\hline
\end{tabular}

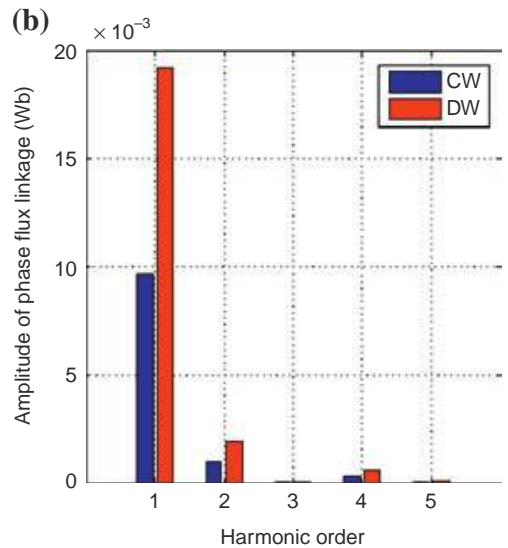

Notes: (a) Waveforms; (b) harmonic spectum. Current density in dc field windings: $\mathrm{J}_{\mathrm{f}}=5 \mathrm{~A} / \mathrm{mm}^{2}$
Winding topologies of flux-switching motors

41

\section{Table III.}

monic winding factors of FSMs with three-phase distributed windings

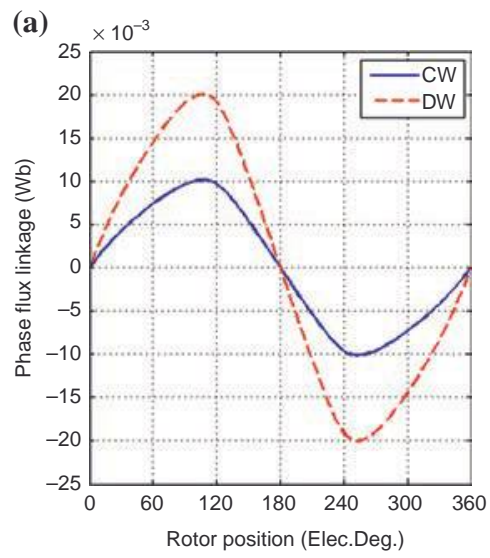

(a) (b)
Figure 7.

FEA results of open-circuit phase

flux linkage in 6/8 dc-excited flux-switching motors with concentrated windings $(\mathrm{CW})$ and distributed windings (DW)

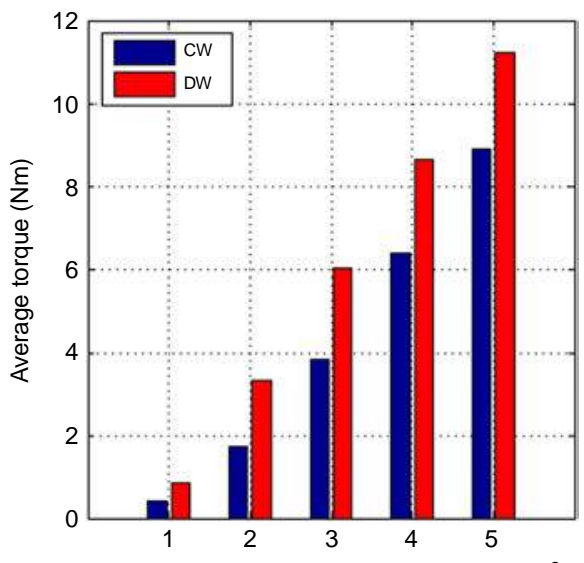

Figure 8.

FEA results of average torque vs current density of $6 / 8$ dc-excited flux-switching motors with concentrated windings (CW) and distributed windings (DW) 
COMPEL 34,1

42

\section{Figure 9.}

Cross-sections of 6/5 dc-excited flux-switching motors (FSM) with indication of different field winding topologies

Figure 10.

End windings in different winding topologies

with concentrated windings. This difference fairly matches that between the winding factors given by the two winding topologies. This increase shows a positive relation between the torque constant and the winding factor of the motor.

However, distributed windings have longer end windings compared to concentrated windings.

This causes additional copper loss. Therefore, distributed windings are not necessarily more efficient than concentrated windings.

\section{Lap windings vs toroidal windings}

For the field winding of DCEFSM, two topologies are presented in Figure 8: lap winding and toroidal winding. In lap windings, each coil is wound around a certain number of stator teeth, while in toroidal windings, coils are wound around the stator yoke (Figure 9).

In toroidal windings, the coil conductors outside the stator yoke do not contribute to the torque production, hence they are part of the end winding, as indicated with dashed line in Figure 10(b). Therefore, the effective coil area in toroidal windings is reduced compared to that in lap windings.

However, with toroidal windings, the total length of end winding is less dependent on the motor diameter and segment number compared to lap windings, hence toroidal windings can be more efficient in motors with relatively large diameter and small stack length (Tang et al., 2010), as shown in Figure 11(b).
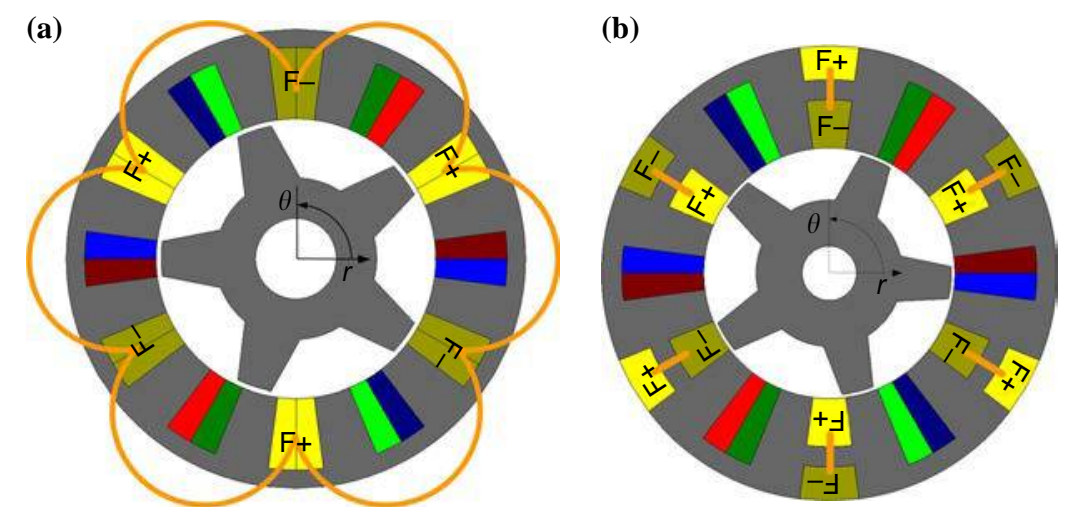

Notes: (a) Lap winding; (b) toroidal winding

(a)

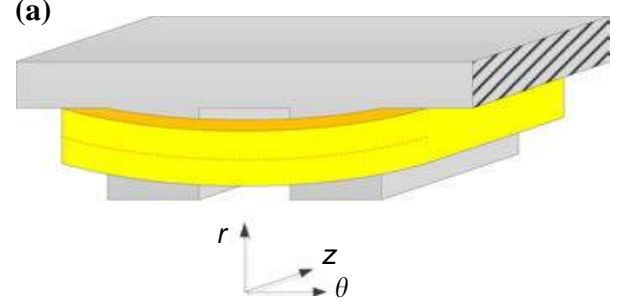

(b)

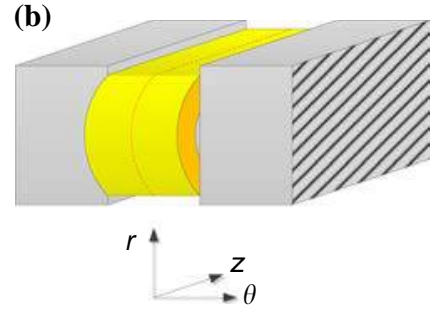

Notes: (a) Lap winding; (b) toroidal winding 
(b)

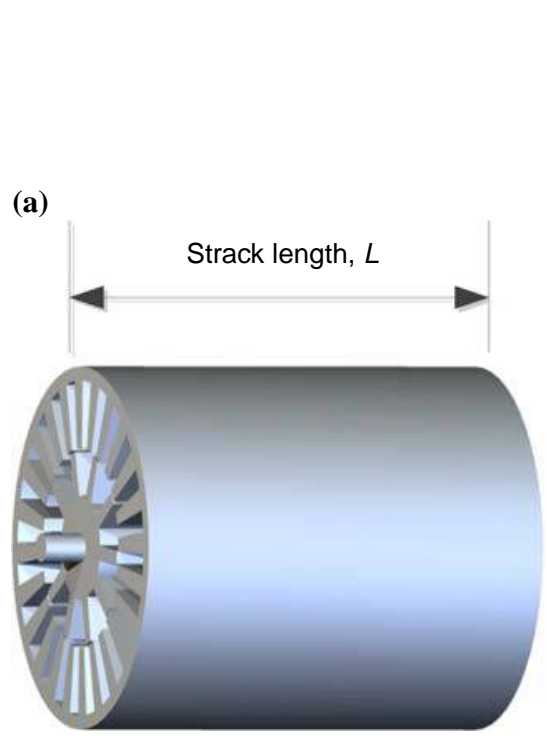

\section{Stator diameter, $D$}

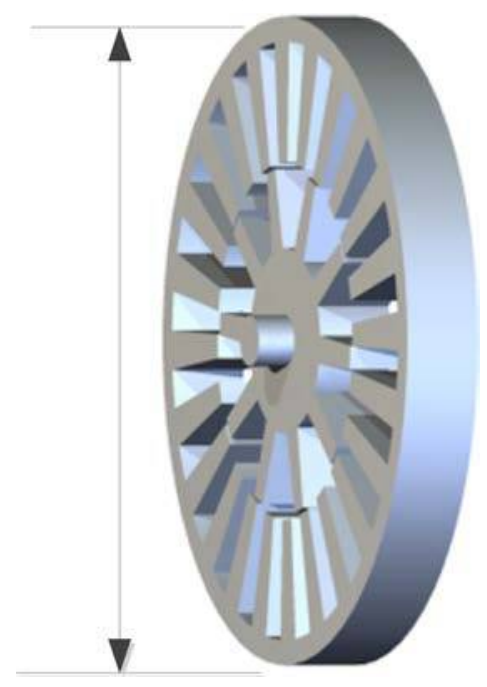

Winding topologies of flux-switching motors

43

Furthermore, toroidal windings contain a large area of exposed coils, which is advantageous for cooling and hence allows higher electrical loading compared to lap windings (Tang et al., 2010).

\section{Conclusions}

In most configurations, the waveform of phase flux linkage of flux switching motors (FSMs) is similar to that in permanent magnet synchronous motors (PMSMs) despite of different principle of torque production. This implies that a similar indication can be used to illustrate winding efficiency within the motor, namely winding factor. This paper has derived a generalized method to calculate this winding factor for FSMs based on the same principle as generally used for PMSMs. In this method the winding factor of FSMs is calculated using only the phase number $m$, the stator-segment number $N_{\mathrm{s}}$, and rotor-tooth number $N_{\mathrm{r}}$ is proposed. Based on this general method, a table of winding factors for FSMs with concentrated windings is obtained. Based on this table, a conclusion is drawn that, for FSMs with concentrated windings, the winding factor increases when the rotor tooth number $N_{\mathrm{r}}$ approaches a multiple of the stator segment number $n N_{\mathrm{s}},(n \in \mathbb{Z})$.

It is also found that with concentrated windings the winding factors of FSMs can never reach its theoretical maximum value, i.e. $k_{\mathrm{w}}=1$. To improve the winding factor, this paper investigated the possibility of implementing distributed windings into a 6-stator-segment, 8-rotor-tooth DCEFSM. The FEA results show that with distributed windings, the winding factor of this motor can reach the maximum value, which is twice of the value obtained with concentrated windings. Under certain conditions, such an improvement in winding factors can potentially enhance the motor performance. Nevertheless, distributed windings also result in an extended end winding, leading to additional copper loss.

Finally, this paper compared two different winding topologies, namely lap winding and toroidal winding, for the field winding of DCEFSM. On the one hand, with certain 
COMPEL 34,1

stator dimensions, lap winding gives a larger effective coil area. On the other hand, toroidal windings can potentially allow higher current density due to the large area of exposed coils. Concerning the efficiency, the superior topology is dependent on the motor dimension, where in the toroidal winding topology, conductors outside the stator yoke do not contribute to the torque production in case of a single air gap motor (Paulides et al., 2011).

\section{References}

Chen, A., Nilssen, R. and Nysveen, A. (2010), "Investigation of a three-phase flux-switching permanent magnet machine for downhole applications", Proceedings XIX International Conference on Electrical Machines - ICEM 2010, Rome, September 6-8.

Chen, J.T. and Zhu, Z.Q. (2010), "Winding configurations and optimal stator and rotor pole combination of flux-switching pm brushless ac machines", IEEE Transaction on Energy Conversion, Vol. 25 No. 2, pp. 293-302.

Ehsani, M., Gao, Y. and Miller, J.M. (2007), "Hybrid electric vehicle: architecture and motor drives", Proceedings of the IEEE, Vol. 95 No. 4, pp. 719-728.

Ilhan, E., Paulides, J.J.H. and Lomonova, E.A. (2010), "Fast torque estimation of in-wheel parallel flux switching machines for hybrid trucks", Journal of Electrical Engineering, Vol. 10 No. 3, pp. 175-182.

Ilhan, E., Gysen, B.L.J., Paulides, J.J.H. and Lomonova, E.A. (2010), “Analytical hybrid model for flux switching permanent magnet machines", IEEE Transactions on Magnetics, Vol. 46 No. 6, pp. 1762-1765.

Lomonova, E.A., Kazmin, E., Tang, Y. and Paulides, J.J.H. (2011), "In-wheel PM motor: compromise between high power density and extended speed capability", COMPEL: The International Journal for Computation and Mathematics in Electrical and Electronic Engineering, Vol. 30 No. 1, pp. 98-116.

Paulides, J.J.H., Gysen, B.L.J., Meessen, K.J., Tang, Y. and Lomonova, E.A. (2011), "Influence of multiple air gaps on the performance of electrical machines with (semi) Halbach magnetization”, IEEE Transaction on Magnetics, Vol. 47 No. 10, pp. 2664-2667.

Tang, Y., Paulides, J.J.H., Kazmin, E.V. and Lomonova, E.A. (2010), "Investigation of winding for permanent magnet in-wheel motors", Proceedings Ecological Vehicles and Renewable Energies, EVER 2010, March 25-28, Monaco.

Zhu, Z.Q. and Howe, D. (2007), "Electrical machines and drives for electric, hybrid, and fuel cell vehicles", Proceedings of the IEEE, Vol. 95 No. 4, pp. 746-765.

\section{Further reading}

Gysen, B.L.J., Ilhan, E., Meessen, K.J., Paulides, J.J.H. and Lomonova, E.A. (2010), "Modeling of flux switching permanent magnet machines with Fourier analysis", IEEE Transactions on Magnetics, Vol. 46 No. 6, pp. 1499-1502.

Hua, W., Zhu, Z.Q., Cheng, M., Pang, Y. and Howe, D. (2005), "Comparison of flux-switching and doubly-salient permanent magnet brushless machines", ICEMS 2005. Proceedings of the Eighth International Conference on Electrical Machines and Sustems, Vol. 1, pp. 165-170.

Ilhan, E., Motoasca, T.E., Paulides, J.J.H. and Lomonova, E.A. (2011), "Conformal mapping: Schwarz-Christoffel method for flux switching PM machines", COMPUMAG 2011, Proceedings of Computational Magnetics, Sydney, July 12-15, pp. 1-4.

Pollock, C., Pollock, H., Barron, R., Sutton, R., Coles, J., Moule, D. and Court, A. (2006), "Fluxswitching motors for automotive applications", IEEE Transactions on Industry Applications, Vol. 42 No. 5, pp. 1177-1184. 
About the authors

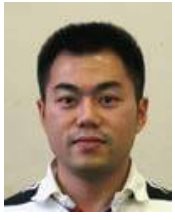

Y. Tang was born in Changsha, China. He received the BEng and MSc Degrees in Electrical Engineering from the Zhejiang University, China in 2003 and 2006, respectively. Since 2007, he has been working at the Eindhoven University of Technology (TU/e), the Netherlands as a Researcher. In 2009, he received a Diploma of Professional Doctorate in Engineering (PDEng). Currently, he is working toward the $\mathrm{PhD}$ Degree in the Electromechanics and Power Electronics (EPE) Group. His research activities are focussed on pre-biased variable field electrical machines. Y. Tang is the corresponding author and can be contacted at: y.tang1@tue.nl

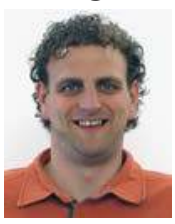

Dr J.J.H. Paulides (M'03-SM'13) was born in Waalwijk, the Netherlands in 1976. He received the BEng Degree from the Technische Hogeschools-Hertogenbosch in 1998 and the MPhil and PhD Degrees in Electrical and Electronical Engineering from the University of Sheffield in 2000 and 2005, respectively. Since 2005, he has been a Research Associate at the Eindhoven University of Technology, the Netherlands. Currently, he holds a Part-Time Assistant Professor position within the Electromechanics and Power Electronics Group working on more electrical sustainable society drive systems. His research activities span all facets of electrical machines, however, in particular permanent magnet machines.

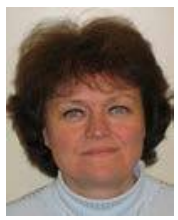

Dr E.A. Lomonova (M'04-SM'07-F'10) was born in Moscow, Russia. She received the MSc (cum laude) and $\mathrm{PhD}$ (cum laude) Degrees in Electromechanical Engineering from the Moscow State Aviation Institute, in 1982 and 1993, respectively. She is currently a Professor with the Department of Electrical Engineering, Eindhoven University of Technology, Eindhoven, the Netherlands. She has worked on electromechanical actuator design, optimization, and the development of advanced mechatronics systems.
Winding topologies of flux-switching motors

For instructions on how to order reprints of this article, please visit our website: 